\title{
The Reference Function of the Lamont Library
}

Mr. Haviland is reference assistant, Lamont Library, Harvard College.

W HERE may I find a map showing the boundaries of the Iron Curtain?

If you were the Emperor Diocletian, what would you do about price-fixing?

Our class is writing on John Brown, where do I find biographical material?

How far has the President's civil rights program progressed?

What is being done to implement the North Atlantic Pact?

What is the population and per cent of people in labor unions in countries throughout the world?

These are typical questions asked at the reference desk, Lamont Library, by undergraduates in Harvard College, and as is usual, this staff is hard put at times to come up with the answer. These questions stem from curiosity, from class assignments, from papers or theses or from reading. Debaters and theme writers from the elementary course in English account for a part of our demand.

Since the opening of Lamont in January 1949, the Harvard undergraduate has had available the services of professional librarians during the hours that the library is open, from 8:45 A.M. to IO:O0 P.M. Monday through Friday and to 5:30 P.M. on Saturday. This amount of staff time is

1 Paper presented at the meeting by the College $\mathrm{Li}$ braries Section, A.C.R.L., Cleveland, July 21 , I950. The writer wishes to call attention to a statement related to this topic which appeared in the Harvard Library Bulletin, Winter 1949. in contrast to the situation found previously by the undergraduate in Widener where service was available only until 5:30 each day and where, indeed, he was in competition with faculty, graduate students and visitors for this service. In Lamont the undergraduate comes first.

The reference function is defined as guidance in the proper and efficient use of the general collection, interpretation of its content and maintenance of an up-to-date ready reference collection. A designated staff qualified to give service implements this function.

A student upon entering the Lamont Library sees books around him. He cannot go to a reading area or from one part of the building to another without passing through a part of the book collection or seeing it at one side. The emphasis in this building is upon exposing the student to the book, and it is hoped that his first contact with this library will be with the books on the shelves. Staff members and card catalogs do not stand in his way as necessary preliminary hurdles, but are provided as assistants when he is in need of help. Herein lies the important departure of the Lamont Library from the past experience of the Harvard student. Never before has he had free access to a general collection of books; a collection selected, housed and administered for his use. And it is here that the reference staff plays its most important role. As an interpreter of the collection and as a guide to its proper and efficient use, this staff functions in a 
way that has not previously been entirely possible.

A student interested in fine arts, for example, will find the histories, biographies, dictionaries and the more important current periodicals in this field in Lamont, together with the texts on the theory of art and the various arts. These materials will support the general course work and the student's immediate interest resulting from his lectures or assigned reading. When he is preparing for term papers or an honors thesis, he will have become thoroughly familiar with the foundations of his field by seeing and using the books on the shelves. From these he may learn of more exhaustive works as listed in footnotes and bibliographies. The reference staff will direct him to these works and to others in the fine arts collections in the Fogg $\mathrm{Mu}$ seum Library and in Widener. The student thus will be saved the trouble of making a new research effort in the more specialized and complete collection of the university, since he will know specifically what he is seeking and where it is to be found. Students in history, literature, government and economics, likewise, will be just as well prepared upon going to Widener since the reference work necessary to decide what to use may frequently be done in Lamont, and a student may then be sent directly to the stack locations where his materials are to be found. One important aspect of the referring of students to another library is that the reference staff sends the student to a specific library, to a particular person in that library and for specified material, and telephones the library to prepare that person to receive the student. This reference preparation is possible for all curricular areas and for any of the departmental and special libraries in the university.

The primary concern of the reference staff is to aid students in the use of the library. The whole staff joins with the reference staff in implementing this principle. The library's educational policy requires that the staff give the student direction to sources in reference work or text where information may be found rather than actually doing the work for him. The reference assistant points out specific sources and then follows up to ascertain if the student has found what he needs. Guides to self-help are used. One means is the scattering throughout the building of copies of the outline of the classification scheme and its subject index. Another means of self-help is the posting on bulletin boards of floor plans upon which have been inserted the numbers of the classification scheme. Also on bulletin boards have been placed brief topical indexes to the classifications with their stack location as well as outlines delineating the content of each level of the building. A student with a specific subject in mind is directed by these means to the point in the book collection where that subject is represented. This direct approach to the book stock should provide the solution for most students. The reference staff is available for those who do not find what they want.

The reference staff experienced mainly informational or directional types of questions during the first six months of operation. This academic year, however, with greater familiarity with the physical organization of the building and collection, the students have asked many more truly reference questions. This increase may be attributed directly to the availability of a professional reference staff prepared to serve the students' needs. Students meeting with success on the first encounter have come back for more and told their friends about our service. After all this is the best publicity.

The Lamont reference collection was selected in the following manner. A librarian on the staff of the Harvard College 
Library compiled a list of recommendations, selected mainly from Mudge's Guide to Reference Books and its Supplements through 1946, and added to this list items found in course lists, in the house libraries (Harvard's seven dormitory libraries, each of over 10,000 volumes), and in reviews in periodicals. A library committee revised this selection.

What is a reference book? There have been various definitions, none of them entirely satisfactory. The term is a loose one referring in general to encylopedias, dictionaries, manuals, handbooks, yearbooks, atlases, bibliographies, indexes and outlines. It may be extended to include any general systematic treatment of a subject. Hence, many of the books found in the general collection in the Lamont Library would, in another library, become a part of the reference collection. The division is a matter of judgment based upon the use to which the library is put by its patrons.

The principles governing the selection of materials for the collection in the Lamont reference room were both general and specific. "Usefulness to undergraduates" was believed to limit the collection. Encyclopedias in English, French, German, Italian and Spanish have been obtained. Language dictionaries in these languages and many others are included, often liberally duplicated. A large atlas collection fills a special case. Encyclopedias and dictionaries of special fields were restricted to those which supplement curricular areas of learning, such as history, philosophy, physics or chemistry. In the same way handbooks, manuals, yearbooks and systematic treatises of particular fields were strictly limited. American and English biographical dictionaries and tools of the Who's Who type are represented. Bibliographies have been included very sparingly, since most of the materials listed would be available in Widener or the departmental or special libraries rather than in Lamont. This does not exclude, however, the general book and periodical bibliographies, lists and indexes so indispensable to all reference work. These types suggest the scope of the reference collection.

Alcove reference collections consisting of an encyclopedia, language dictionaries and reference materials in the fields of the part of the collection located on that level are shelved adjacent to the first, third and fifth level reading areas. These bring basic reference tools closer to the students in the reading areas, or the stacks, than would be possible if the reference collection were shelved entirely in the reference room on the third level. This arrangement also provides a segregated reference area for books that should not leave the building, yet permits these reference tools to be shelved near those parts of the general collection to which they are related.

A further word concerning the principle of selection may be added. The Lamont Library is one of some 75 libraries in the university, most of which are in the vicinity. As one of many, the undergraduate library may provide the general treatises and the fundamental works in special fields and rely on the special library to supply the specialized materials of its field. This principle applies likewise to the reference collection. When a student's need falls beyond the scope of the collection, he is directed to the appropriate library where he may obtain satisfaction. This makes for economy as well as efficiency.

The reference collection that has resulted from this selection consists largely, therefore, of what are usually called the "ready reference" tools. These serve as springboards to the general collection. They introduce the student to a field as a whole, give him a general grasp of a subject or point, or answer a specific question. They supply

(Continued on page 376) 
recorded by their accession dates. Referring once more to the table, it appears that 4.01 per cent and 3.15 per cent of the volumes charged during the two sample weeks had never circulated since 1934. Therefore, if the above-mentioned 76,656 volumes had been stored, 4.01 per cent and 3.15 per cent of the requests received during the two sample weeks would have had to be filled from storage. If the 56,375 volumes never circulated since the end of 1929 had been stored, only 2.02 per cent and 2.01 per cent of the loans made during the sample weeks would have had to be filled from storage.

Several factors are left in doubt by these surveys. No attempt was made to measure use of books in the stacks or the amount of noncirculating material which might fall into the little-used category. There seems little doubt that at least as much of the latter could be stored as of the circulating book stock, and perhaps more, if some of the long serial sets were to be divided along chronological lines. The Stanford surveys are to a large degree exploratory, and they are reported here only as possible approaches to a more scientific basis for determining the advisability of storage in a given situation and for predicting its effect on the public services of a library.

\section{The Lamont Library}

(Continued from page 37I)

information or they lead to sources of more complete or more specific information.

The classic writings, important treatises, basic texts and representative authors are to be found in the general collection. The student is referred to another library for other materials.

The reference staff as well as the other sections of the staff constantly work through the collection to eliminate superseded or unused materials. At the same time, the staff systematically reviews the needs of the undergraduate as reflected in assigned and collateral reading and in special assignments, and selects materials from the current and second-hand book market to recommend for acquisition. An essential working collection and a reference staff thoroughly acquainted with its content are thus achieved.

\section{Conference of Eastern College Librarians}

The Conference of Eastern College Librarians, which did not meet last year, will be held on November 25 at Columbia University. The program will include discussions of library cooperation and new technical developments in library service. 